\title{
Combining GLP-1 Receptor Agonists and Basal Insulin in Older Adults with Type 2 Diabetes: Focus on Lixisenatide and Insulin Glargine
}

\author{
Yehuda Handelsman (D) - Marcel H. A. Muskiet • Graydon S. Meneilly
}

Received: July 18, 2019 / Published online: October 23, 2019

(C) The Author(s) 2019

\begin{abstract}
Estimates suggest that there are currently 122.8 million adults 65-99 years of age living with diabetes, of whom 90-95\% are diagnosed with type 2 diabetes (T2D). Over the past two decades, a greater understanding of the complex and multifactorial pathogenesis of T2D has resulted in the development and introduction of new-generation classes of glucose-lowering therapies, which are now extensively endorsed by prevailing guidelines and are increasingly being used worldwide. These newer agents may further assist in the effective pharmacological management of T2D through the
\end{abstract}

Enhanced Digital Features To view enhanced digital features for this article go to https://doi.org/10.6084/ m9.figshare.9959780.

Y. Handelsman $(\bowtie)$

Metabolic Institute of America, 18372 Clark St. Suite 212, Tarzana, CA 91356, USA

e-mail: yhandelsman@gmail.com

M. H. A. Muskiet

Diabetes Center, Department of Internal Medicine, Amsterdam University Medical Centers (Location

VUMC), 1081 HV Amsterdam, The Netherlands

\section{G. S. Meneilly}

Department of Medicine, The University of British Columbia, 2775 Laurel Street, Vancouver, BC

V5Z1M9, Canada provision of patient-centered care that acknowledges multimorbidity and is respectful of and responsive to individual patient preferences and barriers. Given these considerations, the therapeutic approach in older patients with T2D is complex, particularly in those who have functional dependence, frailty, dementia, or who are at end-of-life. It is currently too early to draw conclusions on the long-term use of newer glucose-lowering agents in this population, as their efficacy and safety in older adults remains largely unknown. In this review, we will discuss considerations for the use of glucose-lowering treatments in older adults, with particular focus on the use of basal insulin and glucagon-like peptide- 1 receptor agonists, and the rationale for the use of combination therapy comprising these agents. Finally, we will review clinical data from studies of the fixed-ratio combination of insulin glargine and lixisenatide in older patients with T2D.

Funding: Sanofi US, Inc.

Keywords: Basal insulin; Fixed-ratio combination; Glucagon-like peptide-1 receptor agonist; GLP-1; Older adults; Type 2 diabetes 


\section{Key Summary Points}

Greater understanding of the complex pathogenesis of type 2 diabetes (T2D), which comprises eight core defects (the ominous octet), has resulted in the development and introduction of new classes of glucose-lowering therapies, the use of which should be tailored according to individual glycemic defects.

Timely escalation of therapy is required for optimal glycemic control, but is often hampered by the traditional 'sequential' approach to treatment that does not address the multiple pathophysiologic defects of T2D.

The therapeutic approach in older ( $\geq 65$ years of age) patients with T2D is complicated by their clinical, cognitive, and functional heterogeneity, polypharmacy and risk of hypoglycemia, with guidelines recommending individualized, less stringent glycemic targets balanced against the risk of hypoglycemia.

Here, we review different treatment options for older patients with T2D, with a focus on the pros and cons associated with the use of glucose-lowering therapies in older patients, with emphasis on insulin therapy and glucagon-like peptide-1 receptor agonists.

In particular, this manuscript reviews data supporting the rationale for the safe and effective use of a fixed-ratio combination comprising insulin glargine 100 units/mL and the glucagon-like peptide- 1 receptor agonist, lixisenatide, in older patients with T2D.

\section{INTRODUCTION}

The International Diabetes Federation estimated that, in 2017, 451 million people 18-99 years of age worldwide were living with diabetes [1]. If trends continue, by 2045, 693 million people will have diabetes, with the largest increases taking place in regions where economies are moving from low- to middle-income levels. Estimates suggest that over onethird of diabetes cases result from population growth and aging, with $28 \%$ attributed to an increase in age-specific prevalence. It is estimated that, globally, there are currently 122.8 million people 65-99 years of age with diabetes, a figure that is expected to increase to 253.4 million in 2045 [1]. Each year, 727 billion USD is spent by people with diabetes on health care alone, which equates to 1 of every 8 dollars spent on health care. The economic burden of diabetes will further increase in parallel with increasing prevalence, particularly among older adults [1].

As highly specialized laboratory testing is required to distinguish between type 1 and type 2 diabetes (T2D), separate global estimates do not exist [2]. Consequently, estimates from high-income countries suggest that T2D accounts for about $90-95 \%$ of all cases of diabetes [3]. Improvements in the understanding of the complex pathogenesis of T2D has resulted in the development of several new-generation glucose-lowering agents with complementary mechanisms of action, which have expanded treatment options and management strategies for patients with T2D. Furthermore, following the 2008 US Food and Drug Administration (FDA) guidance for industry that requires proof of cardiovascular safety as a prerequisite for approval of diabetes treatments, there has been a substantial increase in the understanding of the risks of these treatments, in addition to their benefits, on clinically 
relevant outcomes. With the introduction of an individualized approach to the management of patients with T2D, the potential "value" of glucose-lowering therapy involves more than a cost-benefit analysis, and is based on a "package" of attributes that take into account longterm safety, tolerability, risk of hypoglycemia and weight gain, and suitability in the presence of comorbidities and other medications. This concept of tailoring therapy to patients' needs and preferences plays an important role in treatment choices, particularly for older adults with T2D who, in general, have higher rates of premature death, functional disability, and coexisting illnesses, and are at greater risk for several common geriatric syndromes, such as polypharmacy, cognitive impairment, urinary incontinence, and injurious falls. In this review, we will discuss currently available glucose-lowering treatments, and patient- and drug-specific factors to consider when selecting glucose-lowering therapy for the treatment of older adults ( $\geq 65$ years of age) with T2D. Particular focus is given to the fixed-ratio combination of basal insulin glargine and the glucagon-like peptide-1 receptor agonist (GLP-1 RA), lixisenatide (iGlarLixi). This article is based on previously conducted studies and does not contain any studies with human participants or animals performed by any of the authors.

\section{THE PATHOGENESIS OF T2D AND POTENTIAL CLINICAL IMPLICATIONS}

The core pathophysiologic defects that underlie the development of T2D are pancreatic $\beta$-cell failure and insulin resistance (mostly in skeletal muscle, liver, and adipose tissue). However, it is now recognized that additional defects in multiple organs contribute to the development of T2D. Collectively, these comprise the ominous octet, as postulated by DeFronzo in 2009 (Fig. 1) $[4,5]$, and include dysfunction of adipocytes (accelerated lipolysis), the gastrointestinal tract and entero-endocrine system (incretin deficiency/resistance), $\alpha$-cells (hyperglucagonemia), kidneys (increased glucose reabsorption), and brain (neurotransmitter dysfunction). In addition to the ominous octet, further pathways contributing to hyperglycemia have been delineated, which include systemic low-grade inflammation $[6,7]$, changes in gut microbiota $[8,9]$, and reductions in amylin production [10].

It is now universally recommended that an individualized approach for the treatment for T2D, which includes assessment according to the patient's age, cognitive ability, diabetes complications, duration of disease, comorbidities, and life expectancy, is key for the successful treatment of $\mathrm{T} 2 \mathrm{D}$, as advocated by all prevailing guidelines [11-13].

The traditional approach of "sequential" use of therapy does not adequately address the multiple pathophysiologic processes that contribute to T2D and can often cause a significant delay in controlling the disease [14]. Thus, the use of treatments with complementary mechanisms of action should be considered to address the multiple and specific pathophysiologic disturbances present in T2D. The failure to intensify therapy when treatment targets are not met is termed "therapeutic inertia", which is a widely reported phenomenon that is known to negatively affect clinical outcomes, often through contributing to complications emanating from lack of glycemic control [15-18]. The results from a large retrospective cohort study of 81,573 patients with T2D in the United Kingdom between 2004 and 2006, with followup until 2011, showed that the median time to intensification with insulin was 7.1, 6.1, and 6.0 years for those taking 1, 2, or 3 oral glucoselowering agents, and mean glycated hemoglobin (HbA1c) was 8.7, 9.1, and 9.7\%, respectively [19]. Furthermore, Fu and colleagues analyzed a large US electronic medical records database of records collected between the years 1997 and 2008, and noted a median time to treatment intensification of 14 months in patients with persistent $\mathrm{HbA} 1 \mathrm{c} \geq 7 \%$ on metformin for 6 months [20]. Timely escalation of therapy is needed for disease control, as shown by the rise of HbA1c levels resulting from delaying treatment intensification [14]. The early introduction of combination therapy is an alternative approach [21]. In the EDICT trial, 221 drugnaive patients with recently diagnosed T2D 


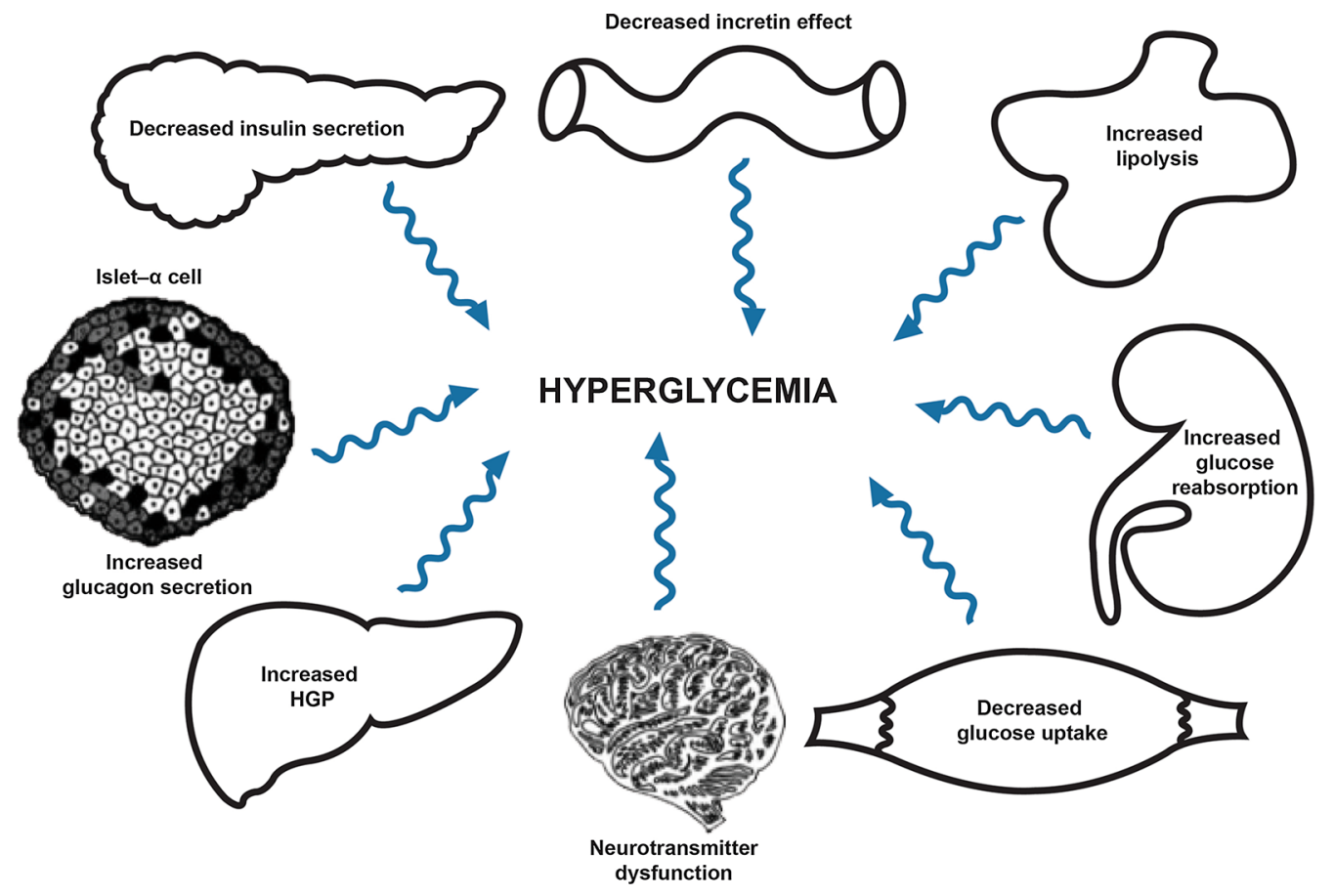

Fig. 1 Physiologic abnormalities contributing to type 2 diabetes. Reproduced with permission from Ref. [5]. American Diabetes Association, Diabetes 2009, Copyright

were randomized to initial simultaneous therapy comprising a combination of agents known to improve insulin secretion and sensitivity (metformin, pioglitazone, and exenatide) or treatment with sequential therapy (i.e., an escalating dose of metformin followed by sequential addition of a sulfonylurea and insulin glargine). Compared with the conventional, stepwise treatment, use of the triple-drug regimen decreased 2-year treatment failure rates by $84 \%$ [22]. Follow-up at 6 years revealed that patients who received combination versus sequential therapy had a significantly greater reduction in $\mathrm{HbA} 1 \mathrm{c}(5.8 \%$ vs. $6.7 \%, p<0.001)$ [23].

\section{MANAGEMENT OF OLDER ADULTS WITH T2D}

The care of older adults with T2D is complicated by their clinical, cognitive, and functional heterogeneity. Whereas some older adults may have longstanding T2D (either diagnosed or and all rights reserved. Material from this publication has been used with the permission of American Diabetes Association

undiagnosed) and significant complications, others may have recent-onset disease with few or no complications [24]. Furthermore, older adults with T2D have a higher incidence of comorbidities compared with their younger counterparts. For example, renal complications affect $41.3 \%$ of patients with T2D aged $>65$ years, and $>60 \%$ of those aged $>75$ years [25], and the risk of all-cause, cardiovascular, and cancer mortality is increased in older adults with uncontrolled T2D, with further risk in individuals with HbA1c $>8 \%$ [26]. Older individuals are also at increased risk of developing hypoglycemia, which can be associated with injurious falls, cognitive impairment, and hospitalization. Some glucose-lowering agents, in particular, insulin and sulfonylureas, can increase the risk of hypoglycemia, particularly in patients with progressive renal insufficiency [27]. Impaired cognitive status can negatively impact patients' ability to self-manage diabetes [27, 28], which can further exacerbate complications. Additionally, polypharmacy, defined as the 
concurrent use of five or more medication classes [28], is more likely to occur in older adults and is associated with severe hypoglycemia. For example, certain antimicrobial agents (i.e., clarithromycin, levofloxacin, sulfamethoxazole-trimethoprim, metronidazole, and ciprofloxacin) can interact with sulfonylureas to increase the risk of hypoglycemia $[29,30]$. Severe hypoglycemia has been linked to an increased risk of dementia [31]. The American Diabetes Association (ADA) Standards of Care 2019 recommend diligent monitoring and avoidance of hypoglycemic events in older adults with T2D, stating that "hypoglycemia should be assessed and managed by adjusting glycemic targets and pharmacologic interventions," adding that "in older adults at increased risk of hypoglycemia, medication classes with low risk of hypoglycemia are preferred" [27].

\section{GUIDELINES FOR INDIVIDUALIZED GLYCEMIC TARGETS IN OLDER ADULTS WITH T2D}

As the treatment of older adults with T2D can be complex, in addition to comprehensive assessment and control of all cardiovascular risk factors, the provision of appropriate treatment to prevent the occurrence of hypoglycemia is of particular importance. Although prevailing international guidelines differ, there is a general agreement that glycemic targets should be individualized with the potential vascular benefit of tight glycemic control being balanced against the risk of hypoglycemia. As such, targets are generally less stringent for older adults, as summarized in Table 1. The American Association of Clinical Endocrinologists/American College of Endocrinology guidelines recommend an HbA1c goal of $\leq 6.5 \%$ for most patients, or $>6.5 \%$ if the lower target cannot be achieved without adverse outcomes [13]. This position is supported by the results of a recent study that suggest that achieving a HbA1c target of $<6.5 \%$ within the first year of diagnosis reduces cardiovascular morbidity and mortality over 10 years [32]. Similarly, the ADA Standards of Care state that, whereas a reasonable HbA1c goal for many nonpregnant adults is $<7 \%$, adults who are older but otherwise healthy with few coexisting chronic illnesses and intact cognitive function and functional status should target a less stringent glycemic goal, such as HbA1c $<7.5 \%$ [11]. The guidelines also state that patients with multiple coexisting chronic illnesses, cognitive impairment, or functional dependence should have a HbA1c target of $<8.0-8.5 \%$ [27]. The International Diabetes Federation guidelines classify patients according to functional dependency, and similarly recommend an HbA1c target of $7.0-7.5 \%$ in those who are functionally independent, and a target of $7.0-8.0 \%$ in those who are functionally dependent, with a further relaxation for individuals who are frail or have dementia [28]. Guidelines from the Department of Veterans Affairs and the Department of Defense recommend HbA1c target ranges (if they can be safely achieved) according to life expectancy and the presence of comorbid conditions [33]. Recently published guidance from the Endocrine Society suggests that reasonable HbA1c targets in older adults who are not receiving treatment that may cause hypoglycemia are $<7.5 \%$ in those who have good health, $<8 \%$ in those who have intermediate health, and $<8.5 \%$ in those with poor health [34].

\section{CONSIDERATIONS FOR CHOICE OF GLUCOSE-LOWERING THERAPY IN OLDER ADULTS WITH T2D}

In addition to lifestyle management, recommending regular exercise that includes aerobic and resistance training and optimal nutrition with adequate protein intake to reduce the risk of frailty, special care is required in prescribing and monitoring pharmacologic therapies in older adults with T2D. Key considerations are highlighted in the ADA standards of medical care for older adults [27]. Briefly, metformin is considered safe for use in patients with estimated glomerular filtration rate $\geq 30 \mathrm{~mL} / \mathrm{min} /$ $1.73 \mathrm{~m}^{2}$, but due to the potential to cause lactic acidosis, use is contraindicated in patients with impaired hepatic function or congestive heart failure. Long-term use of metformin is also associated with vitamin B12 deficiency. 
Table $1 \mathrm{HbAlc}$ targets as specified by standards of care/guidelines

\begin{tabular}{|c|c|c|c|c|c|}
\hline $\begin{array}{l}\text { Stringency } \\
\text { of HbA1c } \\
\text { target }\end{array}$ & $\begin{array}{l}\text { AACE/ACE } \\
{[13]}\end{array}$ & ADA $[27,113]$ & VA [33] & IDF [28] & $\begin{array}{l}\text { The } \\
\text { Endocrine } \\
\text { Society (for } \\
\text { older } \\
\text { patients) [34] }\end{array}$ \\
\hline & $\begin{array}{l}\leq 6.5 \% \text { for } \\
\text { most } \\
\text { patients }\end{array}$ & $\begin{array}{l}<7 \% \text { for many } \\
\text { nonpregnant } \\
\text { adults }\end{array}$ & $\begin{array}{l}6.0-7.0 \% \text { for } \\
\text { patients with a life } \\
\text { expectancy }>10-15 \\
\text { years and absent or } \\
\text { mild microvascular } \\
\text { complications, if it } \\
\text { can be safely } \\
\text { achieved }\end{array}$ & $\begin{array}{l}7.0-7.5 \% \text { in } \\
\text { functionally } \\
\text { independent } \\
\text { patients }\end{array}$ & $\begin{array}{l}<7.5 \% \text { in older } \\
\text { adults with } \\
\text { good health } \\
\text { who are not } \\
\text { taking agents } \\
\text { that may } \\
\text { cause } \\
\text { hypoglycemia }\end{array}$ \\
\hline & \multirow[t]{2}{*}{$\begin{array}{l}>6.5 \% \text { if } \\
\text { the lower } \\
\text { target } \\
\text { cannot be } \\
\text { achieved } \\
\text { without } \\
\text { adverse } \\
\text { outcomes }\end{array}$} & $\begin{array}{l}<7.5 \% \text { in older } \\
\text { adults who are } \\
\text { otherwise } \\
\text { healthy with few } \\
\text { coexisting } \\
\text { chronic } \\
\text { illnesses and } \\
\text { intact cognitive } \\
\text { function and } \\
\text { functional status }\end{array}$ & $\begin{array}{l}7.0-8.5 \% \text { for most } \\
\text { individuals with } \\
\text { established } \\
\text { microvascular or } \\
\text { macrovascular } \\
\text { disease, comorbid } \\
\text { conditions, or } \\
5-10 \text { years life } \\
\text { expectancy, if it can } \\
\text { be safely achieved }\end{array}$ & $\begin{array}{l}7.0-8.0 \% \text { in } \\
\text { those who } \\
\text { are } \\
\text { functionally } \\
\text { dependent }\end{array}$ & $\begin{array}{l}<8 \% \text { in older } \\
\text { adults with } \\
\text { intermediate } \\
\text { health who are } \\
\text { not taking } \\
\text { agents that } \\
\text { may cause } \\
\text { hypoglycemia }\end{array}$ \\
\hline & & $\begin{array}{l}<8.0-8.5 \% \text { in } \\
\text { patients with } \\
\text { multiple } \\
\text { coexisting } \\
\text { chronic } \\
\text { illnesses, } \\
\text { cognitive } \\
\text { impairment, or } \\
\text { functional } \\
\text { dependence }\end{array}$ & $\begin{array}{l}8.0-9.0 \% \text { for } \\
\text { patients with life } \\
\text { expectancy < } 5 \\
\text { years, significant } \\
\text { comorbid conditions, } \\
\text { advanced } \\
\text { complications of } \\
\text { diabetes, or } \\
\text { difficulties in self- } \\
\text { management } \\
\text { attributable to } \\
\text { mental status, } \\
\text { disability, or other } \\
\text { factors such as food } \\
\text { insecurity and } \\
\text { insufficient social } \\
\text { support }\end{array}$ & $\begin{array}{l}\text { Further } \\
\text { relaxation } \\
\text { for } \\
\text { individuals } \\
\text { who are frail } \\
\text { or have } \\
\text { dementia }\end{array}$ & $\begin{array}{l}<8.5 \% \text { in older } \\
\text { adults with } \\
\text { poor health } \\
\text { who are not } \\
\text { taking agents } \\
\text { that may } \\
\text { cause } \\
\text { hypoglycemia }\end{array}$ \\
\hline
\end{tabular}

AACE American Association of Clinical Endocrinologists, $A C E$ American College of Endocrinology, ADA American Diabetes Association, $H b A l c$ glycated hemoglobin, $I D F$ International Diabetes Federation, $V A$ veterans affairs

Thiazolidinediones should be used with caution in patients at risk for congestive heart failure or at risk from falls and/or fractures. Sulfonylureas and other insulin secretagogues may cause hypoglycemia, and long-term experience of use of sodium-glucose cotransporter-2 (SGLT2) inhibitors in older adults is limited.

In older adults with T2D, increases in postprandial plasma glucose (PPG) are particularly prevalent [35], and, as such, treatments that target PPG may be effective in achieving glycemic goals in this population. It is estimated that up to $70 \%$ of the postprandial insulin response to glucose is mediated by incretin hormones [36]. Incretin-based therapies [GLP-1 RAs and dipeptidyl peptidase 4 (DPP-4) inhibitors] lower glucose levels by increasing endogenous insulin secretion and suppressing glucagon release in response to nutrient intake, among other effects [37, 38]. Furthermore, the associated risk for hypoglycemia is low because these agents increase 
insulin secretion and inhibit glucagon release only when glucose levels are elevated [39]. As skeletal muscle is the largest insulin-sensitive tissue in the body, sarcopenia may have a significant contribution to T2D through reduced capacity for glucose metabolism. A number of studies suggest that incretin-based therapies may have a beneficial effect on sarcopenia [40-42]. Patients with T2D also have an increased fracture risk $[43,44]$ and reports suggest that incretin-based therapy may have a beneficial effect on bone mineral density [45-48], but further data are required to confirm this.

DPP-4 inhibitors have few side effects and minimal hypoglycemia risk, which make these agents of particular use for the treatment of older adults with T2D, yet their cost and lower efficacy may be a barrier to some [49]. Two large clinical trials have shown that the DPP-4 inhibitors, saxagliptin and alogliptin, are associated with increased worsening of heart failure in high-risk individuals [50], which prompted the FDA to issue a warning [51].

GLP-1 RAs are effective and generally safe glucose-lowering agents, and some compounds within this class have shown cardiovascular benefits [27]. As they are injectable agents, visual, motor, and cognitive skills are required for appropriate administration. GLP-1 RA may be associated with nausea, vomiting, and diarrhea, and the weight loss that is associated with these drugs may not be desirable in some older adults, particularly those with cachexia [27]. Experience of GLP-1 RA in patients with estimated glomerular filtration rate $<30 \mathrm{~mL} / \mathrm{min} /$ $1.73 \mathrm{~m}^{2}$ is limited, and the use of exenatide is not recommended in this patient population [52]. Although not a concern specific to the treatment of older patients, as GLP-1 RA are therapeutic peptides, the development of antidrug antibodies and hypersensitivity is a possibility when using agents in this class. Varying rates of antibody positivity have been reported in clinical trials of GLP-1 RA [53-57]. In these trials, efficacy and rates of other adverse events were similar in antibody-positive and antibodynegative patients. However, reduced efficacy and increased incidence of allergic and injection-site reactions has been reported in the small percentage of patients with very high antibody titers $[54,58,59]$.

Concerns have also been expressed regarding a possible link between incretin-based therapies and pancreatitis. An assessment of the FDA Adverse Event Reporting System (FAERS) suggested that there is an increased risk of pancreatic cancer associated with DPP-4 inhibitors [60], and results from another FAERS analysis suggested that exenatide and sitagliptin use was associated with an increased risk for pancreatitis [61]. However, several meta-analyses failed to confirm a cause-effect relationship [62-65], and the FDA and European Medicines Agency have jointly agreed that concerns regarding a causal association between incretin-mimetic drugs and pancreatitis or pancreatic cancer are not consistent with the available data [66]. Considerations for the use of lixisenatide in older adults are further discussed below.

\section{USE OF LIXISENATIDE IN OLDER ADULTS WITH T2D}

The GLP-1 RA, lixisenatide, has been studied in over 40 clinical trials and has shown significant beneficial effects on HbA1c reduction and 2-h PPG in numerous settings, including when used as monotherapy (GetGoal-Mono) [56], add-on to oral therapy (GetGoal-S [67], GetGoalF-1 [68], GetGoal-X (vs. exenatide) [69], GetGoal-M [70], GetGoal-P [71]), and add-on to basal insulin (GetGoal-L [72], GetGoal Duo-1 [73], and GetGoal Duo-2 [74]). The use of lixisenatide in older adults was assessed in a meta-analysis of data from 501 patients $\geq 65$ years of age who were enrolled in five of the GetGoal trials in patients on oral glucose-lowering agents. The results confirmed the efficacy of lixisenatide versus placebo in older adults, with no reports of serious hypoglycemic episodes [75]. The efficacy and safety of lixisenatide in non-frail patients $\geq 70$ years of age was confirmed in the randomized, placebo-controlled GetGoal-O study [76]. Patients received once-daily lixisenatide $20 \mathrm{mcg}$ or placebo before breakfast concomitantly with their existing antidiabetic therapy (including insulin and sulfonylureas) for 24 weeks. Compared with those who 
received placebo, patients receiving lixisenatide had least squares mean reductions of $-0.64 \%$ in $\mathrm{HbA1c},-1.32 \mathrm{~kg}$ in body weight, and - $90.9 \mathrm{mg} / \mathrm{dL}$ in 2-h PPG [with a minimal change in fasting plasma glucose (FPG); $5.6 \mathrm{mg} /$ $\mathrm{dL}$ difference]. Adverse events were as expected for a GLP-1 RA; nausea $(25.0 \%$ vs. $7.5 \%)$ and vomiting $(5.7 \%$ vs. $0.6 \%)$ were reported more frequently in the lixisenatide versus placebo group. Hypoglycemia rates were $17.6 \%$ for lixisenatide and $10.3 \%$ for placebo.

\section{LIXISENATIDE AND THE KIDNEY: USE IN PATIENTS WITH RENAL IMPAIRMENT AND POTENTIAL NATRIURETIC EFFECT}

A post hoc analysis of data from the GetGoal clinical trial program (lixisenatide, $n=2869$; placebo, $n=1639$ ), showed that the glucoselowering efficacy and safety outcomes with lixisenatide are not altered in patients with mild or moderate renal impairment [77]. Based on current data, no dose adjustment of lixisenatide is required for patients with mild or moderate renal impairment [59]. There is no therapeutic experience of the use of lixisenatide in patients with severe renal impairment (estimated glomerular filtration rate $<30 \mathrm{~mL} / \mathrm{min}$ ) or endstage renal disease, and, therefore, it is not recommended to use lixisenatide in these populations [59]. As GLP-1 receptor expression has been reported in various locations in the kidney, direct actions of lixisenatide on renal physiology are expected [78]. Indeed, GLP-1 RA agents have been associated with acute natriuresis in overweight, otherwise healthy, adults [79] and in patients with T2D [80]. Interestingly, results from a randomized, open-label trial suggest that, in contrast to long-acting GLP-1 RAs, prolonged treatment with lixisenatide may have a natriuretic effect that is distinct from its glucose-lowering effect [81]. In addition, collective direct and indirect effects of GLP-1 RAs on the renal system have been suggested to improve renal outcomes in patients with T2D, independently of their glucose-lowering action [78]. The ELIXA study assessed the cardiovascular safety of lixisenatide versus placebo in 6068 patients with T2D who had experienced an acute coronary event in the previous 180 days [82]. In a post hoc analysis of the study, renal outcomes were assessed by baseline urine albumin-to-creatinine ratio (UACR) status [83]. After 108 weeks, in patients with baseline macroalbuminuria (UACR $>300 \mathrm{mg} / \mathrm{g}$ ), lixisenatide reduced the placebo-adjusted mean percentage change in UACR by $39.2 \%(95 \%$ confidence interval 9.8 to $-68.5 \% ; p=0.007$ ). The $21.1 \%$ change in patients with microalbuminuria did not reach statistical significance. Furthermore, lixisenatide was associated with a reduced risk of new-onset macroalbuminuria when adjusted for baseline HbA1c [hazard ratio, $0.81 \quad(95 \%$ confidence interval 0.66-0.99; $p=0.040)]$ and for baseline and on-trial HbA1c [hazard ratio, $0.82(0.67-1.00 ; p=0.049)]$. For the purpose of this manuscript, this post hoc analysis was repeated in patients $\geq 65$ years of age. The results remained consistent, with a significant reduction in UACR progression in patients with macroalbuminuria $(\geq 300 \mathrm{mg} / \mathrm{g}$ ) who received lixisenatide versus placebo (percentage change from baseline to week 108 in UACR $-45.3 \%$ vs. $-4.4 \% ; p=0.042$ ), although only a numerical trend for patients with microalbuminuria $(\geq 30$ to $<300 \mathrm{mg} / \mathrm{g}$ ) in favor of lixisenatide was observed $(-16.2$ vs. $-4.7 ; p=0.563$; data on file).

\section{INSULIN THERAPY IN OLDER ADULTS WITH T2D}

Many patients with T2D will eventually require insulin as the disease progresses and pancreatic $\beta$-cell function declines [84]. Numerous formulations of insulin are available, which have differing durations of action. The effectiveness of treatment with insulin is highly dependent on appropriate use, patient selection, and patient training to achieve appropriate adjustment of dose for changes in diet, activity, or weight, and titration to acceptable and safe glucose targets. The main advantage of insulin over other glucose-lowering medications is that insulin lowers glucose over a wide range, to almost any glycemic target as limited by hypoglycemia. 


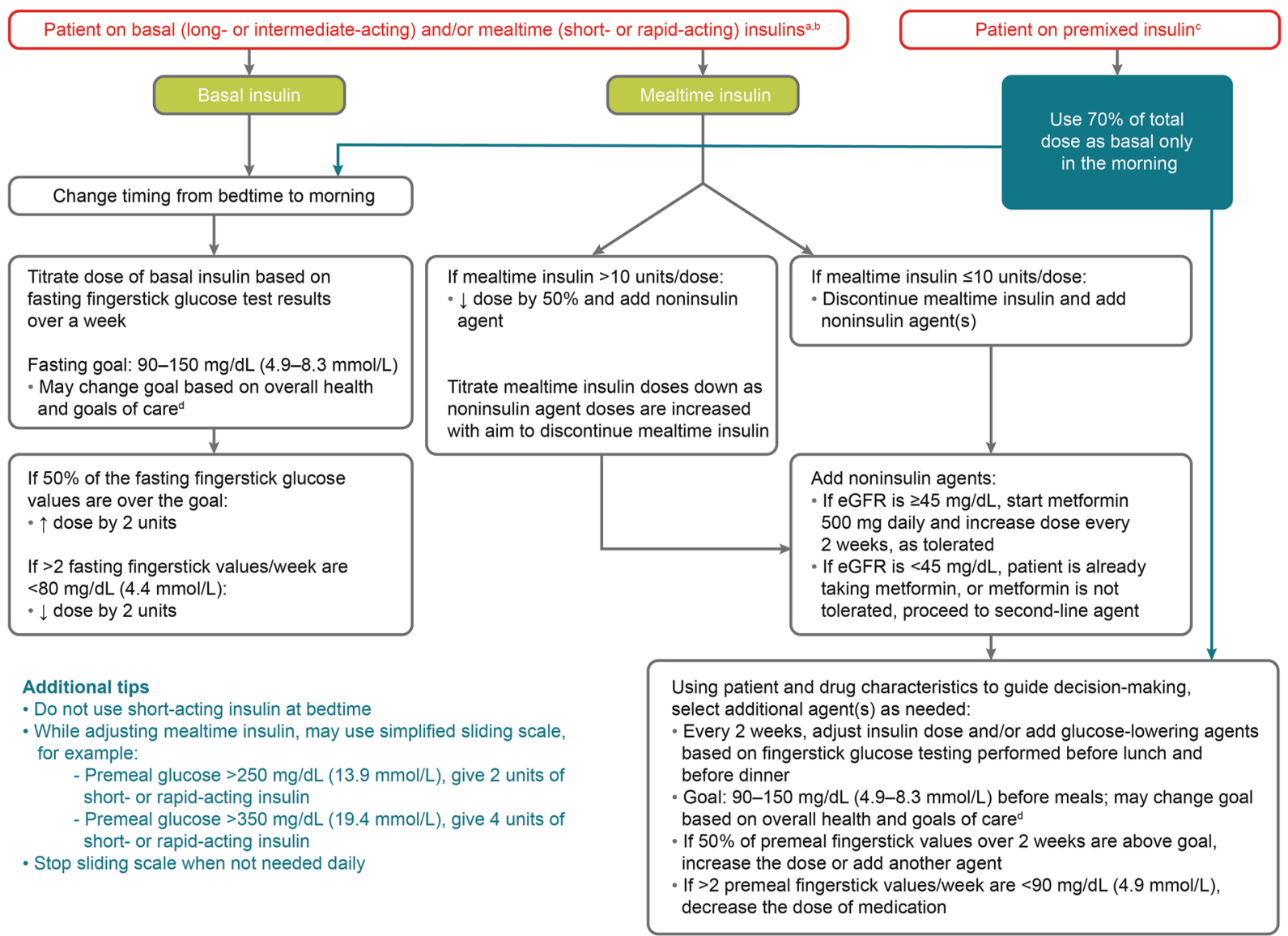

Fig. 2 Simplification of complex insulin therapy. eGFR estimated glomerular filtration rate. a Basal insulins: glargine U-100 and U-300, detemir, degludec, and human neutral protamine Hagedorn (NPH). $b$ Mealtime insulins: short-acting (regular human insulin) or rapid-acting

Beyond hypoglycemia, the disadvantages of insulin include weight gain and the need for injection, frequent titration for optimal efficacy, and glucose monitoring. Pre-mixed insulin preparations containing rapid-acting and intermediate-acting insulin analogs to allow coverage of both basal and prandial needs with a single injection can be used in older adults $[85,86]$, but are not without risk in patients with intercurrent disease or in those in whom caloric intake is inadequate or unstable. Complex basal-bolus insulin regimens comprising multiple injections to address basal and prandial requirements may not be appropriate for use in older adults with cognitive, visual, or dexterous impairment [27], and have been (lispro, aspart, and glulisine). c Premixed insulins: 70/30, $75 / 25$, and 50/50 products. American Diabetes Association, Diabetes 2019, Copyright and all rights reserved. Material from this publication has been used with the permission of American Diabetes Association

associated with an increased risk of hypoglycemia. Simplification of insulin regimens for older adults with T2D can be a complex and protracted process (Fig. 2).

Fear of hypoglycemia can be a barrier to initiating insulin therapy, both by the patient and the physician [87]. The improved clinical profiles of long-acting basal insulin analogs along with increased convenience and a reduced risk of hypoglycemia, make basal insulin more accessible as a treatment for older adults with T2D. Results from the APOLLO study revealed that a single dose of basal insulin glargine when used in combination with oral glucose-lowering agents was as effective in patients with T2D as three times-daily prandial 
insulin lispro in reducing $\mathrm{HbA1c}$, and was associated with a significantly lower risk of hypoglycemia, less weight gain, and a greater improvement in treatment satisfaction [88].

To summarize, the current typical clinical course of T2D treatment involves the initiation of basal insulin treatment before the addition of prandial or bolus insulin. Basal-bolus regimens, in which patients take basal insulin once or twice a day and a bolus insulin before each meal, is now regarded as the last line in this therapeutic progression. Yet, even with the use of intensive basal-bolus insulin treatments, the achievement of glycemic targets is often limited by inadequate insulin dose titration because of concerns about the risks of hypoglycemia and weight gain. In this setting, an ideal glucoselowering treatment regimen would be one that couples achievement of glycemic control with a low propensity for hypoglycemia and weight gain.

\section{RATIONALE FOR COMBINATION THERAPY COMPRISING GLP-1 RAs AND BASAL INSULIN}

One of the mechanisms through which GLP-1 RAs achieve glycemic control is stimulation of $\beta$-cell insulin secretion [89]; as such, it follows that GLP-1 RA treatment in patients with marked $\beta$-cell failure will not achieve sufficient insulin secretion, thereby reducing the efficacy of this approach in patients with more advanced disease. Indeed, studies have shown that longer duration of diabetes and severe insulin deficiency is associated with reduced efficacy of longer-acting GLP-1 RAs [90-92], which is especially important in older adults who may have longstanding disease. With this in mind, the combination of a GLP-1 RA with basal insulin remains a logical approach to T2D treatment, based on the complementary effects of these two agents. Insulin acts primarily on FPG through increasing peripheral glucose uptake and inhibition of hepatic glucose production [93].

GLP-1 RAs can either provide short-lived (short-acting compounds) or continuous (longacting compounds) activation of the GLP-1 receptor, often leading to tachyphylaxis [94]. Short-acting GLP-1 RAs, such as lixisenatide, reduce PPG levels principally through a delay in gastric emptying [38, 95]. Conversely, longeracting GLP-1 RAs such as liraglutide continuously activate GLP-1 receptors and primarily reduce FPG levels through glucose-dependent stimulation of insulin secretion and glucagon inhibition; however, the benefit of long-term treatment with long-acting GLP-1 RAs remains under debate [96]. The approach of combining a GLP-1 RA with basal insulin overcomes barriers to achieving glycemic control that can be associated with their individual use, in addition to addressing a number of the multiple pathophysiologic processes that contribute to the development of T2D. When combined with basal insulin, which improves FPG and is effective in patients with longer duration disease, GLP-1 RAs provide improved glycemic control without increased hypoglycemia risk. Furthermore, the combination therapy can offset the weight gain observed with insulin therapy. This was demonstrated in the GetGoal Duo-2 study, which compared the efficacy and safety of lixisenatide with prandial insulin (glulisine, once or three times daily) as add-on therapy to insulin glargine with or without metformin in patients with uncontrolled T2D (HbA1c between $\geq 7 \%$ and $\leq 9 \%$ and mean FPG $\leq 140 \mathrm{mg} / \mathrm{dL}$ ) [74]. HbA1c decreased from 8.5 to $7.9 \%$ during the run-in period and further at week 26 , to $7.2 \%$ with lixisenatide, $7.2 \%$ with glulisine once daily, and $7.0 \%$ with glulisine three times daily. Symptomatic hypoglycemia (35.9\%, 46.5\%, and 52.4\%, respectively) and body weight $(-0.6 \pm 0.3 \mathrm{~kg},+1.0 \pm 0.3 \mathrm{~kg}$, and $+1.4 \pm 0.3 \mathrm{~kg}$, respectively) were lower in patients who received lixisenatide versus insulin glulisine. As expected, more gastrointestinal events occurred with lixisenatide $(35.2 \%, 8.6 \%$, and $7.5 \%$, respectively). Patients receiving lixisenatide were twice as likely to achieve the composite outcome of $\mathrm{HbA} 1 \mathrm{c}<7 \%$ without weight gain or documented symptomatic hypoglycemia.

In 2016, two different once-daily fixed-ratio combination products containing basal insulin plus a GLP-1 RA gained approval for use in patients with T2D: insulin glargine plus 
lixisenatide (iGlarLixi; SOLIQUA ${ }^{\circledR}$ [97] /SULIQUA [98]) and insulin degludec plus liraglutide (IDegLira; XULTOPHY ${ }^{\circledR}$ [99] /LYXUMIA [100]). The FDA has recently extended the use of SOLIQUA 100/33 and XULTOPHY as an adjunct to diet and exercise.

\section{FIXED-RATIO COMBINATION OF INSULIN GLARGINE 100 UNITS/ ML AND LIXISENATIDE 33 MCG/ML}

SOLIQUA $^{\circledR} 100 / 33$ (iGlarLixi) is a titratable, fixed-ratio combination of insulin glargine 100 Units $/ \mathrm{mL}$ (iGlar) and lixisenatide $33 \mathrm{mcg} / \mathrm{mL}$, which can deliver iGlar over a range of 15-60 Units/day in steps of one unit in a once-daily injection. The product is available as 3:1 ratio of iGlar:lixisenatide, in which lixisenatide is available in a range of 5 to a maximum of 20 mcg/day, allowing gradual up-titration of lixisenatide, which follows that of insulin glargine (to a maximum daily dose of 60 Units), thereby mitigating the gastrointestinal effects of lixisenatide. The efficacy and safety of iGlarLixi has been demonstrated in patients with T2D inadequately controlled on oral glucose-lowering agents (LixiLan-O study [101]), in those with T2D inadequately controlled on insulin (LixiLan-L study [102]), and in those in whom T2D is inadequately controlled on a combination of GLP-1 RA and metformin (LixiLan-G study [103]). In the LixiLan-O study, iGlarLixi improved 2-h postprandial glycemic control versus iGlar or lixisenatide alone, and a higher proportion of patients who received iGlarLixi achieved HbA1c $<7.0 \%$ or $\leq 6.5 \%$ compared with iGlar and/or lixisenatide. iGlarLixi was associated with considerably fewer nausea and vomiting events than lixisenatide alone [101]. In both the LixiLan-O and LixiLan-L studies, patients who received iGlarLixi had significantly greater reductions in $\mathrm{HbA1c}$ with no increase in documented symptomatic hypoglycemia (blood glucose $<70 \mathrm{mg} / \mathrm{dL}$ ) or weight gain as compared with iGlar or lixisenatide $[101,102]$. LixiLan-G was a randomized, openlabel, 26-week trial that compared switching to iGlarLixi $(n=257)$ versus continued daily or weekly GLP-1 RA therapy in patients with uncontrolled T2D (HbA1c 7-9\%) despite therapy with a maximum tolerated dose of a onceor twice-daily or once-weekly GLP-1 RA and metformin ( \pm pioglitazone \pm SGLT2 inhibitor). Reductions from baseline (7.8\%) in HbA1c were significantly $(p<0.0001)$ greater for iGlarLixi (6.7\%) versus GLP-1 RA (7.4\%), irrespective of daily or weekly GLP-1 RA administration. Additionally, more patients who received iGlarLixi achieved HbA1c targets and the composite endpoint of HbA1c $<7 \%$ without documented symptomatic hypoglycemia $(<54 \mathrm{mg}$ / dL). Documented symptomatic hypoglycemia, nausea, and vomiting rates were low, but greater with iGlarLixi than those continuing on GLP-1 RA [103]. Measurement of anti-drug antibodies (ADAs) in the LixiLan-O and LixiLan-L trials revealed that, after 30 weeks of treatment with iGlarLixi, formation of anti-insulin glargine antibodies occurred in $21.0 \%$ and $26.2 \%$ of patients, respectively. Approximately 93\% of patients with anti-insulin glargine antibodies showed cross-reactivity to human insulin. The formation of anti-lixisenatide antibodies developed in approximately $43 \%$ of patients [97]. In the LixiLan-O study, the proportions of patients with any adverse events adjudicated as allergic reaction was $1.3 \%, 0.6 \%$, and $0.9 \%$ in the iGlarLixi, iGlar, and lixisenatide groups [101]. In the LixiLan-L study, no allergic reactions were reported in the iGlarLixi group [102]. There was no meaningful difference in the efficacy or safety profiles of antibody-positive or -negative populations for either anti-insulin glargine or anti-lixisenatide antibody patients in either of the iGlarLixi phase 3 trials.

Similar efficacy and safety results have been reported for iDegLira in the DUAL program in patients receiving sulfonylurea treatment with or without metformin [104], in patients receiving basal insulin and metformin with or without sulfonylurea/glinides [105], and in patients receiving a GLP-1 RA and oral therapy [106]. Data from clinical trials that measured antibody formation revealed that, at end of treatment, $11.1 \%$ of patients had insulin degludec-specific antibodies, with $30.8 \%$ of patients having antibodies that cross-reacted with human insulin, and $2.1 \%$ of patients had anti-liraglutide 
antibodies. Similar to iGlarLixi, antibody formation was not correlated with reduced efficacy of IDegLira [99]. While the measurement of ADAs is routine in T2D clinical trials of therapeutic proteins, incidence rates vary widely due to different methodologies, timing of sample collection, sample handling, concomitant medications, underlying disease, and interpretation of data. For these reasons, comparisons of immunogenicity data across therapies can be misleading.

The results of an exploratory analysis of the LixiLan-L study showed that iGlarLixi provided consistent improvements in glycemic control, and mitigated (up to $-0.9 \mathrm{~kg}$ ) the gain in body weight observed with iGlar (up to $+1.1 \mathrm{~kg}$ ), regardless of $\mathrm{HbA} 1 \mathrm{c}$ subgroup $(<8 \%, \geq 8 \%)$, duration of T2D $(<10, \geq 10$ years), or body mass index $\left(<30, \geq 30 \mathrm{~kg} / \mathrm{m}^{2}\right)$ [95]. Similar results have been reported from a post hoc analysis of the LixiLan-O study [107], which are further supported by a recently published analysis demonstrating superior glycemic control with iGlarLixi compared with iGlar or lixisenatide in patients with a baseline HbA1c $\geq 9 \%$, with reductions in HbA1c of $-2.9 \%,-2.5 \%$, and $-1.7 \%$ for iGlarLixi, iGlar, and lixisenatide, respectively [108]. The results of another post hoc analysis of the LixiLan-L study showed that reductions in $\mathrm{HbA1c}$ to week 30 were greater for iGlarLixi than iGlar, irrespective of screening HbA1c subgroup ( $\leq 8 \%$ : -1.1 vs. $-0.5 ;<8 \%$ to $\leq 9 \%$ : -1.4 vs. $-1.0 ;>9 \%$ : -2.4 vs. -1.8 ; all $p<0.0001)$. Also, more patients who received iGlarLixi versus iGlar achieved HbA1c $<7 \%$, irrespective of screening HbA1c subgroup ( $\leq 8 \%$ : $74.2 \%$ vs. $37.2 \%$; $<8 \%$ to $\leq 9 \%: 54.7 \%$ vs. $31.6 \%$; $>9 \%$ : $52.2 \%$ vs. $23.5 \%)$ [109].

\section{USE OF IGLARLIXI IN OLDER ADULTS WITH T2D}

Simplification of therapy is likely to reduce nonadherence, resulting in the ability to maintain treatment for a longer duration [110]. Furthermore, the adoption of individualized treatment goals, as recommended by diabetes treatment guidelines, means that older adults with T2D could benefit from improved treatment regimens.

The efficacy and safety of iGlarLixi was assessed in patients $\geq 65$ versus $<65$ years of age in an analysis using patient-level data from the LixiLan-O and LixiLan-L studies [111]. In both studies, more patients who received iGlarLixi versus iGlar or lixisenatide reached the HbA1c target of $<7 \%$, and the results were similar for older ( $\geq 65$ years) and younger ( $<65$ years) patients, although the absolute percentages were lower in the LixiLan-L study compared with the LixiLan-O study. Reductions in $\mathrm{HbA} 1 \mathrm{c}$ at week 30 were greater for iGlarLixi (LixiLan-O, - 1.45\%; LixiLan-L, - 1.11\%) versus iGlar (LixiLan-O, - 1.15\%; LixiLan-L, $-0.48 \%$ ) in both studies, as was the proportion of patients achieving the composite endpoint of HbA1c $<7 \%$ with no weight gain and no documented symptomatic hypoglycemia (iGlarLixi: LixiLan-O, 30.1\%; LixiLan-L, 26.4\%; iGlar: LixiLan-O, 14.0\%; LixiLan-L, 8.4\%). In both studies, there was a small difference in weight loss versus gain for patients who received iGlarLixi versus iGlar. Mean event rates per patient-year of symptomatic hypoglycemia were similar for iGlarLixi and iGlar (1.42 vs. 1.89 ) in the LixiLan-O study, but were lower for iGlarLixi than iGlar in the LixiLan-L study $(2.84$ vs. 4.91). Rates of nausea for iGlarLixi (12-14\%) were meaningfully lower than for lixisenatide $(21 \%)$, as were rates of vomiting $(3.6-4.5 \%$ vs. $6.9 \%)$. Rates of diarrhea were similar between iGlarLixi and iGlar.

An analysis of data from LixiLan-O and LixiLan-L trials was undertaken to determine if outcomes (weight loss, documented symptomatic hypoglycemia, serious adverse events, or gastrointestinal adverse events) in older patients ( $>65$ years of age) differed according to the absence or presence of comorbidities. Comorbidities were classified based upon The Healthcare Effectiveness Data and Information Set 2016 measures, which define glycemic goals in patients with T2D by age ( $<$ or $>65$ years) and health status (comorbidities). Analysis of covariance was used to compare HbA1c concentrations at week 30 by comorbidity group, adjusted by the baseline HbA1c value. There were no differences in older patients with or 
without comorbidities in either the LixiLan-O or LixiLan-L trials, except for slightly greater weight loss in patients with versus without comorbidities in the LixiLan-O trial (data on file).

A similar post hoc analysis using data from patients $\geq 65$ versus $<65$ years of age who were enrolled in the DUAL II, III, and V studies showed that decreases in HbA1c were greater with IDegLira than with basal insulin or unchanged GLP-1 RA, and hypoglycemia rates were lower with IDegLira versus basal insulin and higher versus unchanged GLP-1 RA [112].

\section{CONCLUSIONS}

The prevalence of T2D in older adults will continue to increase in line with the rise in agerelated factors, such as insulin resistance, deficient insulin secretion, and changes in body composition and loss of muscle mass. Management of T2D in older adults is complex due to the clinical, cognitive, and functional heterogeneity of this population, and, although some older adults with T2D may achieve disease control with oral glucose-lowering agents, many will require insulin as the disease progresses. Avoidance of hypoglycemia is particularly important in this patient population, which becomes more achievable given the recent advances in pharmacologic treatment and recommendations for the adoption of individualized treatment goals.

Combining basal insulin therapy with a GLP$1 \mathrm{RA}$ in a fixed-ratio preparation may be an effective and simplified treatment option for older adults with T2D that combines high glucose-lowering efficacy with no increase in the risk of hypoglycemia and no weight gain. The efficacy of iGlarLixi in patients $\geq 65$ years of age has been shown to be comparable with that of younger counterparts, and it can be used as an adjunct to diet and exercise in adults for the treatment of $\mathrm{T} 2 \mathrm{D}$ that is inadequately controlled on oral glucose-lowering agents, GLP-1 $\mathrm{RA}$, or basal insulin. iGlarLixi does not require dose adjustment in patients with mild or moderate renal impairment, and post hoc data suggest that lixisenatide may reduce progression of renal complications, which may prove to be beneficial for the large proportion of older adults with T2D who have renal dysfunction and/or albuminuria. iGlarLixi offers a simplified treatment approach that targets the majority of pathophysiologic defects of T2D without increased risk of hypoglycemia and with weight neutrality and an incidence of nausea/vomiting that due to the gradual titration of lixisenatide, is markedly reduced compared with values observed with lixisenatide alone.

\section{ACKNOWLEDGEMENTS}

Funding. This review, the Rapid Service and Open Access Fees were funded by Sanofi US, Inc., Bridgewater, NJ, USA.

Medical Writing Assistance. The authors received medial writing support in the preparation of this manuscript provided by Helen Jones, PhD, CMPP, of Evidence Scientific Solutions, funded by Sanofi US, Inc.

Authorship. All named authors meet the International Committee of Medical Journal Editors (ICMJE) criteria for authorship for this article, take responsibility for the integrity of the work as a whole, and have given their approval for this version to be published.

Disclosures. Yehuda Handelsman has received research grants, consulted with, and received speaker honoraria from Aegerion, Amarin, Amgen, AstraZeneca, Bristol-Myers Squibb, Boehringer Ingelheim, Boehringer Ingelheim Lilly, Gan \& Lee, Gilead, Intarcia, Janssen, Lexicon, Lilly, Merck, Merck-Pfizer, Mylan, Novo Nordisk, Regeneron, Sanofi, and Target. Marcel H.A. Muskiet has served as a consultant and speaker for Eli Lilly \& Co, Novo Nordisk, and Sanofi, and all honoraria are paid to the Amsterdam University Medical Centers (location VUMC), Amsterdam, the Netherlands. Graydon S. Meneilly participated on a GSM Advisory Board for Merck and Novo Nordisk, and received speaking fees from Boehringer Ingelheim, Lilly, and Merck. 
Compliance with Ethics Guidelines. This article is based on previously conducted studies and does not contain any studies with human participants or animals performed by any of the authors.

Data Availability. Data sharing is not applicable to this article as no datasets were generated or analyzed during the current study.

Open Access. This article is distributed under the terms of the Creative Commons Attribution-NonCommercial 4.0 International License (http://creativecommons.org/licenses/ by-nc/4.0/), which permits any noncommercial use, distribution, and reproduction in any medium, provided you give appropriate credit to the original author(s) and the source, provide a link to the Creative Commons license, and indicate if changes were made.

\section{REFERENCES}

1. IDF Diabetes Atlas. Eighth edition. International Diabetes Federation website. 2017. https:// diabetesatlas.org/resources/2017-atlas.html. Accessed May 2019.

2. World Health Organization. Global Deport on Diabetes. 2016. https://apps.who.int/iris/bitstream/ handle/10665/204871/9789241565257_eng.pdf; jsessionid=0614B2DFE5379CF79F3E57AA27D915 33 ? sequence $=1$. Accessed April 2019.

3. Centers for Disease Control and Prevention. National Diabetes Statistics Report, 2017. Estimates of Diabetes and Its Burden in the United States. Atlanta, GA: Centers for Disease Control and Prevention, U.S. Dept of Health and Human Services; 2017. https://www.cdc.gov/diabetes/data/ statistics/statistics-report.html. Accessed April 2019.

4. DeFronzo RA, Eldor R, Abdul-Ghani M. Pathophysiologic approach to therapy in patients with newly diagnosed type 2 diabetes. Diabetes Care. 2013;36(Suppl 2):S127-38.

5. Defronzo RA. Banting Lecture. From the triumvirate to the ominous octet: a new paradigm for the treatment of type 2 diabetes mellitus. Diabetes. 2009;58:773-95.

6. Pietropaolo M, Barinas-Mitchell E, Kuller LH. The heterogeneity of diabetes: unraveling a dispute: is systemic inflammation related to islet autoimmunity? Diabetes. 2007;56:1189-97.

7. Subauste A, Gianani R, Chang AM, et al. Islet autoimmunity identifies a unique pattern of impaired pancreatic beta-cell function, markedly reduced pancreatic beta cell mass and insulin resistance in clinically diagnosed type 2 diabetes. PLoS ONE. 2014;9:e106537.

8. Allin KH, Nielsen T, Pedersen O. Mechanisms in endocrinology: gut microbiota in patients with type 2 diabetes mellitus. Eur J Endocrinol. 2015; 172:R167-77.

9. Tai N, Wong FS, Wen L. The role of gut microbiota in the development of type 1, type 2 diabetes mellitus and obesity. Rev Endocr Metab Disord. 2015;16:55-65.

10. Schwartz SS, Epstein S, Corkey BE, Grant SF, Gavin JR 3rd, Aguilar RB. The time is right for a new classification system for diabetes: rationale and implications of the $\beta$-cell-centric classification schema. Diabetes Care. 2016;39:179-86.

11. American Diabetes Association. 6. Glycemic targets: standards of medical care in diabetes-2019. Diabetes Care. 2019;42(Suppl 1):S61-70.

12. Davies MJ, D'Alessio DA, Fradkin J, et al. Management of hyperglycemia in type 2 diabetes. A consensus report by the American Diabetes Association (ADA) and the European Association for the Study of Diabetes (EASD). Diabetes Care. 2018;2018(41): 2669-701.

13. Garber AJ, Abrahamson MJ, Barzilay JI, et al. Consensus statement by the American Association of Clinical Endocrinologists and American College of Endocrinology on the Comprehensive Type 2 Diabetes Management Algorithm-2019 executive summary. Endocr Pract. 2019;25:69-100.

14. Del Prato S, Felton AM, Munro N, Nesto R, Zimmet $\mathrm{P}$, Zinman B. Improving glucose management: ten steps to get more patients with type 2 diabetes to glycaemic goal. Recommendations from the Global Partnership for Effective Diabetes Management. Int J Clin Pract. 2005;59:1345-55.

15. Brown JB, Nichols GA, Perry A. The burden of treatment failure in type 2 diabetes. Diabetes Care. 2004;27:1535-40.

16. Khunti K, Davies MJ. Clinical inertia versus overtreatment in glycaemic management. Lancet Diabetes Endocrinol. 2018;6:266-8.

17. Blonde L, Raccah D, Lew E, et al. Treatment intensification in type 2 diabetes: a real-world study of 
2-OAD regimens, GLP-1 RAs, or basal insulin. Diabetes Ther. 2018;9:1169-84.

18. Khunti K, Millar-Jones D. Clinical inertia to insulin initiation and intensification in the UK: a focused literature review. Prim Care Diabetes. 2017;11:3-12.

19. Khunti K, Wolden ML, Thorsted BL, Andersen M, Davies MJ. Clinical inertia in people with type 2 diabetes: a retrospective cohort study of more than 80,000 people. Diabetes Care. 2013;36:3411-7.

20. Fu AZ, Qiu Y, Davies MJ, Radican L, Engel SS. Treatment intensification in patients with type 2 diabetes who failed metformin monotherapy. Diabetes Obes Metab. 2011;13:765-9.

21. Cahn A, Cefalu WT. Clinical considerations for use of initial combination therapy in type 2 diabetes. Diabetes Care. 2016;39(Suppl 2):S137-45.

22. Abdul-Ghani MA, Puckett C, Triplitt C, et al. Initial combination therapy with metformin, pioglitazone and exenatide is more effective than sequential addon therapy in subjects with new-onset diabetes. Results from the Efficacy and Durability of Initial Combination Therapy for Type 2 Diabetes (EDICT): a randomized trial. Diabetes Obes Metab. 2015;17:268-75.

23. Abdul-Ghani M, Puckett CL Jr, Triplitt CL, et al. Durable HbA1c reduction with initial combination therapy with metformin/pioglitazone/exenatide in subjects with new-onset diabetes-six-year followup of the EDICT study. Diabetes. 2018;67(Suppl 1):123-OR.

24. Selvin E, Coresh J, Brancati FL. The burden and treatment of diabetes in elderly individuals in the US. Diabetes Care. 2006;29:2415-9.

25. Russo GT, De Cosmo S, Viazzi F, et al. Diabetic kidney disease in the elderly: prevalence and clinical correlates. BMC Geriatr. 2018;18:38.

26. Palta P, Huang ES, Kalyani RR, Golden SH, Yeh HC. Hemoglobin $\mathrm{A}_{1 \mathrm{c}}$ and mortality in older adults with and without diabetes: results from the National Health and Nutrition Examination Surveys (1988-2011). Diabetes Care. 2017;40:453-60.

27. American Diabetes Association. 12. Older adults: standards of medical care in diabetes-2019. Diabetes Care. 2019;42(Suppl 1):S139-47.

28. International Diabetes Federation. Managing older people with type 2 diabetes: Global guideline. 2013. https://www.idf.org/e-library/guidelines/78-globalguideline-for-managing-older-people-with-type-2diabetes.html. Accessed Feb 2019.
29. Parekh TM, Raji M, Lin YL, Tan A, Kuo YF, Goodwin JS. Hypoglycemia after antimicrobial drug prescription for older patients using sulfonylureas. JAMA Intern Med. 2014;174:1605-12.

30. Rossio R, Arcudi S, Peyvandi F, Piconi S. Persistent and severe hypoglycemia associated with trimethoprim-sulfamethoxazole in a frail diabetic man on polypharmacy: a case report and literature review. Int J Clin Pharmacol Ther. 2018;56:86-9.

31. Feinkohl I, Aung PP, Keller M, on behalf of the Edinburgh Type 2 Diabetes Study (ET2DS) Investigators, et al. Severe hypoglycemia and cognitive decline in older people with type 2 diabetes: the Edinburgh type 2 diabetes study. Diabetes Care. 2014;37:507-15.

32. Laiteerapong N, Ham SA, Gao Y, et al. The legacy effect in type 2 diabetes: impact of early glycemic control on future complications (the diabetes and aging study). Diabetes Care. 2019;42:416-26.

33. The Management of Type 2 Diabetes Mellitus in Primary Care Work Group. VA/DoD clinical practice guideline for the management of type 2 diabetes mellitus in primary care. Version 5.0. 2017. https:// www.healthquality.va.gov/guidelines/CD/diabetes/ VADoDDMCPGFinal508.pdf. Accessed Feb 2019.

34. LeRoith D, Biessels GJ, Braithwaite SS, et al. Treatment of diabetes in older adults: an Endocrine Society clinical practice guideline. J Clin Endocrinol Metab. 2019;104:1520-74.

35. Munshi MN, Pandya N, Umpierrez GE, DiGenio A, Zhou R, Riddle MC. Contributions of basal and prandial hyperglycemia to total hyperglycemia in older and younger adults with type 2 diabetes mellitus. J Am Geriatr Soc. 2013;61:535-41.

36. Cernea S. The role of incretin therapy at different stages of diabetes. Rev Diabet Stud. 2011;8:323-38.

37. Nauck M. Incretin therapies: highlighting common features and differences in the modes of action of glucagon-like peptide-1 receptor agonists and dipeptidyl peptidase-4 inhibitors. Diabetes Obes Metab. 2016;18:203-16.

38. Smits MM, Tonneijck L, Muskiet MH, Kramer MH, Cahen DL, van Raalte DH. Gastrointestinal actions of glucagon-like peptide-1-based therapies: glycaemic control beyond the pancreas. Diabetes Obes Metab. 2016;18:224-35.

39. Garber AJ. Long-acting glucagon-like peptide 1 receptor agonists: a review of their efficacy and tolerability. Diabetes Care. 2011;34(Suppl 2):S279-84. 
40. Hong Y, Lee JH, Jeong KW, Choi CS, Jun HS. Amelioration of muscle wasting by glucagon-like peptide-1 receptor agonist in muscle atrophy. J Cachexia Sarcopenia Muscle. 2019;10:903-18.

41. Campins L, Camps M, Riera A, Pleguezuelos E, Yebenes JC, Serra-Prat M. Oral drugs related with muscle wasting and sarcopenia. A review. Pharmacology. 2017;99:1-8.

42. Rizzo MR, Barbieri M, Fava I, et al. Sarcopenia in elderly diabetic patients: role of dipeptidyl peptidase 4 inhibitors. J Am Med Dir Assoc. 2016;17:896-901.

43. Hamann C, Kirschner S, Gunther KP, Hofbauer LC. Bone, sweet bone-osteoporotic fractures in diabetes mellitus. Nat Rev Endocrinol. 2012;8:297-305.

44. Vestergaard P. Discrepancies in bone mineral density and fracture risk in patients with type 1 and type 2 diabetes-a meta-analysis. Osteoporos Int. 2007;18:427-44.

45. Ceccarelli E, Guarino EG, Merlotti D, et al. Beyond glycemic control in diabetes mellitus: effects of incretin-based therapies on bone metabolism. Front Endocrinol (Lausanne). 2013;4:73.

46. Hygum K, Starup-Linde J, Langdahl BL. Diabetes and bone. Osteoporos Sarcopenia. 2019;5:29-37.

47. Ma RC, Xu G. Incretin action on bone: an added benefit? J Diabetes Investig. 2015;6:267-8.

48. Monami M, Dicembrini I, Antenore A, Mannucci E. Dipeptidyl peptidase- 4 inhibitors and bone fractures: a meta-analysis of randomized clinical trials. Diabetes Care. 2011;34:2474-6.

49. Davidson JA. The placement of DPP-4 inhibitors in clinical practice recommendations for the treatment of type 2 diabetes. Endocr Pract. 2013;19:1050-61.

50. Packer M. Worsening heart failure during the use of DPP-4 inhibitors: pathophysiological mechanisms, clinical risks, and potential influence of concomitant antidiabetic medications. JACC Heart Fail. 2018;6:445-51.

51. FDA Drug Safety Communication: FDA adds warnings about heart failure risk to labels of type 2 diabetes medicines containing saxagliptin and alogliptin. US Food and Drug Administration website. 2016. https://www.fda.gov/drugs/drug-safetyand-availability/fda-drug-safety-communicationfda-adds-warnings-about-heart-failure-risk-labelstype-2-diabetes. Accessed May 2019.

52. Tuttle KR, Bakris GL, Bilous RW, et al. Diabetic kidney disease: a report from an ADA consensus conference. Diabetes Care. 2014;37:2864-83.
53. Fineman MS, Mace KF, Diamant M, et al. Clinical relevance of anti-exenatide antibodies: safety, efficacy and cross-reactivity with long-term treatment. Diabetes Obes Metab. 2012;14:546-54.

54. VICTOZA [summary of product characteristics]. https://www.ema.europa.eu/en/documents/produ ct-information/victoza-epar-product-information en.pdf. Accessed Aug 2019.

55. Buse JB, Garber A, Rosenstock J, et al. Liraglutide treatment is associated with a low frequency and magnitude of antibody formation with no apparent impact on glycemic response or increased frequency of adverse events: results from the Liraglutide Effect and Action in Diabetes (LEAD) trials. J Clin Endocrinol Metab. 2011;96:1695-702.

56. Fonseca VA, Alvarado-Ruiz R, Raccah D, Boka G, Miossec P, Gerich JE, on behalf of the EFC6018 GetGoal-Mono Study Investigators. Efficacy and safety of the once-daily GLP-1 receptor agonist lixisenatide in monotherapy: a randomized, double-blind, placebo-controlled trial in patients with type 2 diabetes (GetGoal-Mono). Diabetes Care. 2012;35:1225-31.

57. Ratner RE, Rosenstock J, Boka G, Investigators DRIS. Dose-dependent effects of the once-daily GLP-1 receptor agonist lixisenatide in patients with Type 2 diabetes inadequately controlled with metformin: a randomized, double-blind, placebo-controlled trial. Diabet Med. 2010;27:1024-32.

58. BYETTA [summary of product characteristics]. https://www.accessdata.fda.gov/drugsatfda_docs/ label/2009/021773s9s11s18s22s25lbl.pdf. Accessed Aug 2019.

59. ADLYXIN (lixisenatide) for subcutaneous use [prescribing information]. Bridgewater, NJ: sanofiaventis US LLC; 2016. https://www.accessdata.fda. gov/drugsatfda_docs/label/2016/208471orig1s0001 bl.pdf. Accessed June 2019.

60. Feng X, Cai A, Dong K, et al. Assessing pancreatic cancer risk associated with dipeptidyl peptidase 4 Inhibitors: data mining of FDA adverse event reporting system (FAERS). J Pharmacovigil. 2013;1:1000110.

61. Elashoff M, Matveyenko AV, Gier B, Elashoff R, Butler PC. Pancreatitis, pancreatic, and thyroid cancer with glucagon-like peptide-1-based therapies. Gastroenterology. 2011;141:150-6.

62. Li X, Zhang Z, Duke J. Glucagon-like peptide 1-based therapies and risk of pancreatitis: a selfcontrolled case series analysis. Pharmacoepidemiol Drug Saf. 2014;23:234-9.

63. Monami M, Dicembrini I, Nardini C, Fiordelli I, Mannucci E. Glucagon-like peptide-1 receptor 
agonists and pancreatitis: a meta-analysis of randomized clinical trials. Diabetes Res Clin Pract. 2014;103:269-75.

64. Faillie JL, Babai S, Crepin S, et al. Pancreatitis associated with the use of GLP-1 analogs and DPP-4 inhibitors: a case/non-case study from the French Pharmacovigilance Database. Acta Diabetol. 2014;51:491-7.

65. Giorda CB, Sacerdote C, Nada E, Marafetti L, Baldi I, Gnavi R. Incretin-based therapies and acute pancreatitis risk: a systematic review and meta-analysis of observational studies. Endocrine. 2015;48: 461-71.

66. Egan AG, Blind E, Dunder K, et al. Pancreatic safety of incretin-based drugs-FDA and EMA assessment. N Engl J Med. 2014;370:794-7.

67. Rosenstock J, Hanefeld M, Shamanna P, et al. Beneficial effects of once-daily lixisenatide on overall and postprandial glycemic levels without significant excess of hypoglycemia in type 2 diabetes inadequately controlled on a sulfonylurea with or without metformin (GetGoal-S). J Diabetes Complicat. 2014;28:386-92.

68. Bolli GB, Munteanu M, Dotsenko S, et al. Efficacy and safety of lixisenatide once daily vs. placebo in people with type 2 diabetes insufficiently controlled on metformin (GetGoal-F1). Diabet Med. 2014;31:176-84.

69. Rosenstock J, Raccah D, Korányi L, et al. Efficacy and safety of lixisenatide once daily versus exenatide twice daily in type 2 diabetes inadequately controlled on metformin: a 24-week, randomized, open-label, active-controlled study (GetGoal-X). Diabetes Care. 2013;36:2945-51.

70. Ahren B, Leguizamo Dimas A, Miossec P, Saubadu S, Aronson R. Efficacy and safety of lixisenatide oncedaily morning or evening injections in type 2 diabetes inadequately controlled on metformin (GetGoal-M). Diabetes Care. 2013;36:2543-50.

71. Pinget M, Goldenberg R, Niemoeller E, MuehlenBartmer I, Guo H, Aronson R. Efficacy and safety of lixisenatide once daily versus placebo in type 2 diabetes insufficiently controlled on pioglitazone (GetGoal-P). Diabetes Obes Metab. 2013;15:1000-7.

72. Riddle MC, Aronson R, Home P, et al. Adding oncedaily lixisenatide for type 2 diabetes inadequately controlled by established basal insulin: a 24-week, randomized, placebo-controlled comparison (GetGoal-L). Diabetes Care. 2013;36:2489-96.

73. Riddle MC, Forst T, Aronson R, et al. Adding oncedaily lixisenatide for type 2 diabetes inadequately controlled with newly initiated and continuously titrated basal insulin glargine: a 24-week, randomized, placebo-controlled study (GetGoal-Duo 1). Diabetes Care. 2013;36:2497-503.

74. Rosenstock J, Guerci B, Hanefeld M, on behalf of the GetGoal Duo-2 Trial Investigators, et al. Prandial options to advance basal insulin glargine therapy: testing lixisenatide plus basal insulin versus insulin glulisine either as basal-plus or basal-bolus in type 2 diabetes: the GetGoal Duo-2 trial. Diabetes Care. 2016;39:1318-28.

75. Hanefeld M, Berria R, Lin J, et al. Lixisenatide treatment for older patients with type 2 diabetes mellitus uncontrolled on oral antidiabetics: metaanalysis of five randomized controlled trials. Adv Ther. 2014;31:861-72.

76. Meneilly GS, Roy-Duval C, Alawi H, on behalf of the GetGoal-O Trial Investigators, et al. Lixisenatide therapy in older patients with type 2 diabetes inadequately controlled on their current antidiabetic treatment: the GetGoal-O randomized trial. Diabetes Care. 2017;40:485-93.

77. Hanefeld M, Arteaga JM, Leiter LA, et al. Efficacy and safety of lixisenatide in patients with type 2 diabetes and renal impairment. Diabetes Obes Metab. 2017;19:1594-601.

78. Muskiet MHA, Tonneijck L, Smits MM, et al. GLP-1 and the kidney: from physiology to pharmacology and outcomes in diabetes. Nat Rev Nephrol. 2017;13:605-28.

79. Muskiet MH, Tonneijck L, Smits MM, et al. Acute renal haemodynamic effects of glucagon-like peptide-1 receptor agonist exenatide in healthy overweight men. Diabetes Obes Metab. 2016;18:178-85.

80. Tonneijck L, Smits MM, Muskiet MHA, et al. Acute renal effects of the GLP-1 receptor agonist exenatide in overweight type 2 diabetes patients: a randomised, double-blind, placebo-controlled trial. Diabetologia. 2016;59:1412-21.

81. Tonneijck L, Muskiet MHA, Smits MM, et al. Postprandial renal haemodynamic effect of lixisenatide vs once-daily insulin-glulisine in patients with type 2 diabetes on insulin-glargine: an 8-week, randomised, open-label trial. Diabetes Obes Metab. 2017;19:1669-80.

82. Pfeffer MA, Claggett B, Diaz R, for the ELIXA Investigators, et al. Lixisenatide in patients with type 2 diabetes and acute coronary syndrome. N Engl J Med. 2015;373:2247-57.

83. Muskiet MHA, Tonneijck L, Huang Y, et al. Lixisenatide and renal outcomes in patients with type 2 diabetes and acute coronary syndrome: an exploratory analysis of the ELIXA randomised, 
placebo-controlled trial. Lancet Diabetes Endocrinol. 2018;6:859-69.

84. Philis-Tsimikas A. Initiating basal insulin therapy in type 2 diabetes: practical steps to optimize glycemic control. Am J Med. 2013;126:S21-7.

85. Elizarova S, Galstyan GR, Wolffenbuttel BH. Role of premixed insulin analogues in the treatment of patients with type 2 diabetes mellitus: a narrative review. J Diabetes. 2014;6:100-10.

86. Coscelli C, Calabrese G, Fedele D, et al. Use of premixed insulin among the elderly. Reduction of errors in patient preparation of mixtures. Diabetes Care. 1992;15:1628-30.

87. Berard L, Bonnemaire M, Mical M, Edelman S. Insights into optimal basal insulin titration in type 2 diabetes: results of a quantitative survey. Diabetes Obes Metab. 2018;20:301-8.

88. Bretzel RG, Nuber U, Landgraf W, Owens DR, Bradley C, Linn T. Once-daily basal insulin glargine versus thrice-daily prandial insulin lispro in people with type 2 diabetes on oral hypoglycaemic agents (APOLLO): an open randomised controlled trial. Lancet. 2008;371:1073-84.

89. Drucker DJ. The biology of incretin hormones. Cell Metab. 2006;3:153-65.

90. Jones AG, McDonald TJ, Shields BM, for the PRIBA Study Group, et al. Markers of $\beta$-cell failure predict poor glycemic response to GLP-1 receptor agonist therapy in type 2 diabetes. Diabetes Care. 2016;39:250-7.

91. Thong KY, Jose B, Sukumar N, on behalf of the ABCD nationwide exenatide audit contributors, et al. Safety, efficacy and tolerability of exenatide in combination with insulin in the Association of British Clinical Diabetologists nationwide exenatide audit. Diabetes Obes Metab. 2011;13:703-10.

92. Thong KY, Mcgowan BM, Htay T, ABCD Nationwide Liraglutide Audit contributors, et al. Insulin treatment and longer diabetes duration both predict poorer glycaemic response to liraglutide treatment in type 2 diabetes: the Association of British Clinical Diabetologists Nationwide Liraglutide Audit. Br J Diabetes Vasc Dis. 2015;15:169.

93. Riddle M, Umpierrez G, DiGenio A, Zhou R, Rosenstock J. Contributions of basal and postprandial hyperglycemia over a wide range of A1C levels before and after treatment intensification in type 2 diabetes. Diabetes Care. 2011;34:2508-14.

94. Meier JJ. GLP-1 receptor agonists for individualized treatment of type 2 diabetes mellitus. Nat Rev Endocrinol. 2012;8:728-42.
95. Wysham C, Bonadonna RC, Aroda VR, on behalf of the LixiLan-L trial investigators, et al. Consistent findings in glycaemic control, body weight and hypoglycaemia with iGlarLixi (insulin glargine/ lixisenatide titratable fixed-ratio combination) vs insulin glargine across baseline $\mathrm{HbA1c}$, BMI and diabetes duration categories in the LixiLan-L trial. Diabetes Obes Metab. 2017;19:1408-15.

96. Abdulreda MH, Rodriguez-Diaz R, Caicedo A, Berggren PO. Liraglutide compromises pancreatic $\beta$ cell function in a humanized mouse model. Cell Metab. 2016;23:541-6.

97. SOLIQUA ${ }^{\circledR} 100 / 33$ (insulin glargine and lixisenatide injection), for subcutaneous use [prescribing information]. Bridgewater, NJ: sanofi-aventis US LLC; 2019. http://products.sanofi.us/Soliqua100-33/Sol iqua100-33.pdf. Accessed May 2019.

98. SULIQUA [summary of product characteristics]. Paris, France: sanofi-aventis groupe. https://www. ema.europa.eu/en/documents/product-information/ suliqua-epar-product-information_en.pdf. Accessed June 2019.

99. XULTOPHY ${ }^{\circledR} \quad 100 / 3.6$ (insulin degludec and liraglutide injection), for subcutaneous use [prescribing information]. Plainsboro, NJ: Novo Nordisk Inc.; 2019. https://www.novo-pi.com/xultophy100 36.pdf. Accessed May 2019.

100. LYXUMIA [summary of product characteristics]. Paris, France: sanofi-aventis groupe. https://www. ema.europa.eu/en/documents/product-information/ lyxumia-epar-product-information_en.pdf. Accessed June 2019.

101. Rosenstock J, Aronson R, Grunberger G, on behalf of the LixiLan-O Trial Investigators, et al. Benefits of LixiLan, a titratable fixed-ratio combination of insulin glargine plus lixisenatide, versus insulin glargine and lixisenatide monocomponents in type 2 diabetes inadequately controlled on oral agents: the LixiLan-O randomized trial. Diabetes Care. 2016;39:2026-35.

102. Aroda VR, Rosenstock J, Wysham C, on behalf of the LixiLan-L Trial Investigators, et al. Efficacy and safety of LixiLan, a titratable fixed-ratio combination of insulin glargine plus lixisenatide in type 2 diabetes inadequately controlled on basal insulin and metformin: the LixiLan-L randomized trial. Diabetes Care. 2016;39:1972-80.

103. Blonde L, Rosenstock J, Del Prato S, et al. LixiLan-G: a randomized trial assessing switching to iGlarLixi vs. continuation of daily or weekly GLP-1RA in T2D inadequately controlled by a GLP-1RA and OAD(s). Diabetes. 2019;68(Suppl 1):149-OR.

104. Rodbard HW, Bode BW, Harris SB, et al. Safety and efficacy of insulin degludec/liraglutide (IDegLira) 
added to sulphonylurea alone or to sulphonylurea and metformin in insulin-naive people with Type 2 diabetes: the DUAL IV trial. Diabetes Med. 2017;34:189-96.

105. Buse JB, Vilsboll T, Thurman J, et al. Contribution of liraglutide in the fixed-ratio combination of insulin degludec and liraglutide (IDegLira). Diabetes Care. 2014;37:2926-33.

106. Linjawi S, Bode BW, Chaykin LB, et al. The efficacy of IDegLira (insulin degludec/liraglutide combination) in adults with type 2 diabetes inadequately controlled with a GLP-1 receptor agonist and oral therapy: DUAL III randomized clinical trial. Diabetes Ther. 2017;8:101-14.

107. Davies MJ, Leiter LA, Guerci B, et al. Impact of baseline glycated haemoglobin, diabetes duration and body mass index on clinical outcomes in the LixiLan-O trial testing a titratable fixed-ratio combination of insulin glargine/lixisenatide (iGlarLixi) vs insulin glargine and lixisenatide monocomponents. Diabetes Obes Metab. 2017;19:1798-804.

108. Davies MJ, Russell-Jones D, Barber TM, et al. Glycaemic benefit of iGlarLixi in insulin-naive type 2 diabetes patients with high HbA1c or those with inadequate glycaemic control on two oral antihyperglycaemic drugs in the LixiLan-O randomized trial. Diabetes Obes Metab. 2019;21:1967-72.

109. Niemoeller E, Souhami E, Wu Y, Jensen KH. iGlarLixi reduces glycated hemoglobin to a greater extent than basal insulin regardless of levels at screening: post hoc analysis of LixiLan-L. Diabetes Ther. 2018;9:373-82.

110. Peyrot M, Rubin RR, Kruger DF, Travis LB. Correlates of insulin injection omission. Diabetes Care. 2010;33:240-5.

111. Handelsman Y, Chovanes C, Dex T, et al. Efficacy and safety of insulin glargine/lixisenatide (iGlarLixi) fixed-ratio combination in older adults with type 2 diabetes. J Diabetes Complications. 2019;33:236-42.

112. Lingvay I, Handelsman Y, Linjawi S, et al. Efficacy and safety of IDegLira in older patients with type 2 diabetes. Endocr Pract. 2019;25:144-55.

113. American Diabetes Association. 9. Pharmacologic approaches to glycemic treatment: standards of medical care in diabetes-2019. Diabetes Care. 2019;42(Suppl 1):S90-102. 